\title{
Correction to: Lower COVID-19 Mortality in Patients with Type 2 Diabetes Mellitus Taking Dipeptidyl Peptidase-4 Inhibitors: Results from a Turkish Nationwide Study
}

Rifat Emral · Cem Haymana · Ibrahim Demirci · Ilker Tasci • Mustafa Sahin · Erman Cakal • Naim Ata • Ugur Unluturk · Tevfik Demir · Derun Ertugrul · Ibrahim Sahin · Aysegül Atmaca • Osman Celik •

Murat Caglayan · Kazim Yalcin Arga · Selcuk Dagdelen · Serpil Salman · Ilhan Satman · Alper Sonmez

Published online: September 24, 2021

(C) The Author(s) 2021

Correction to: Diabetes Ther

https://doi.org/10.1007/s13300-021-01133-8

In the Original Article, the twelfth author name was published incorrectly. The correct name is Ibrahim Sahin.

The original article has been corrected.

The original article can be found online at https://doi. org/10.1007/s13300-021-01133-8.

R. Emral $(\bowtie) \cdot$ M. Sahin

Department of Endocrinology and Metabolism, Faculty of Medicine, Ankara University, Ankara, Turkey

e-mail: rifatemral@gmail.com

C. Haymana · I. Demirci

Department of Endocrinology and Metabolism, Gulhane Training and Research Hospital, University of Health Sciences, Ankara, Turkey

I. Tasci

Department of Internal Medicine, Gulhane Faculty of Medicine and Gulhane Training and Research Hospital, University of Health Sciences, Ankara, Turkey

\section{E. Cakal}

Department of Endocrinology and Metabolism, Faculty of Medicine, Diskapi Yildirim Beyazit Training and Research Hospital, University of Health Sciences, Ankara, Turkey

\section{N. Ata}

Department of Strategy Development, Ministry of Health of the Republic of Turkey, Ankara, Turkey

U. Unluturk · S. Dagdelen

Department of Endocrinology and Metabolism, Faculty of Medicine, Hacettepe University, Ankara, Turkey

\section{T. Demir}

Department of Endocrinology and Metabolism, Dokuz Eylul University, Faculty of Medicine, Izmir, Turkey

\section{Ertugrul}

Department of Endocrinology and Metabolism, Faculty of Medicine, Kecioren Training and Research Hospital, University of Health Sciences, Ankara, Turkey 
Open Access. This article is licensed under a Creative Commons Attribution-NonCommercial 4.0 International License, which permits any non-commercial use, sharing, adaptation, distribution and reproduction in any medium or format, as long as you give appropriate credit to the original author(s) and the source, provide a link to the Creative Commons licence, and indicate if changes were made. The images or other third party material in this article are

\section{Sahin}

Department of Endocrinology and Metabolism, Faculty of Medicine, Inonu University, Malatya, Turkey

\author{
A. Atmaca \\ Department of Endocrinology and Metabolism, \\ Faculty of Medicine, Ondokuz Mayis University, \\ Samsun, Turkey \\ O. Celik \\ Public Hospitals General Directorate, Ministry of \\ Health of the Republic of Turkey, Ankara, Turkey \\ M. Caglayan \\ Ankara Provincial Health Directorate, Ankara, \\ Turkey \\ K. Y. Arga \\ Department of Bioengineering, Faculty of \\ Engineering, Marmara University, Istanbul, Turkey
}

included in the article's Creative Commons licence, unless indicated otherwise in a credit line to the material. If material is not included in the article's Creative Commons licence and your intended use is not permitted by statutory regulation or exceeds the permitted use, you will need to obtain permission directly from the copyright holder. To view a copy of this licence, visit http://creativecommons.org/licenses/by$\mathrm{nc} / 4.0 /$.

K. Y. Arga · I. Satman

Institute of Public Health and Chronic Diseases, The Health Institutes of Turkey, Istanbul, Turkey

S. Salman

Department of Endocrinology and Metabolism, Medica Clinic, Istanbul, Turkey

\section{Satman}

Department of Endocrinology and Metabolism, Faculty of Medicine, Istanbul University, Istanbul, Turkey

A. Sonmez

Department of Endocrinology and Metabolism, Gulhane Faculty of Medicine and Gulhane Training and Research Hospital, University of Health Sciences, Ankara, Turkey 